\title{
Development of a vegetative propagation protocol for Asclepias tuberosa
}

\author{
Mary Lewis, Matthew Chappell, Paul A Thomas, Donglin Zhang, and Ockert Greyvenstein
}

This open access article is distributed under the terms of the CC-BY-NC-ND license (http://creativecommons.org/ licenses/byncnd/4.0) and is freely available online at: http://npj.uwpress.org.
$\begin{array}{ll}A B S T R A C T & \text { ABST }\end{array}$

This article describes the first published report of a commercially viable vegetative propagation protocol for butterfly milkweed (Asclepias tuberosa L. [Apocynaceae]). Milkweed (Asclepias L.) species are regarded as a superior North American native pollinator taxa. Restoration of species into disturbed sites and increasing its use in managed landscape environments are a means of sustaining and promoting many threatened and endangered pollinators that rely on Asclepias spp. for nectar in the adult stage and for forage in the juvenile stage of development. Unlike restoration efforts that predominantly rely on seedproduced plants, commercial ornamental production relies heavily on vegetative propagation. However, vegetative propagation of Asclepias spp. on a commercial scale has been limited due to the lack of published propagation protocol(s). This study employed vegetative cuttings of Asclepias tuberosa taken at 2 maturities and treated with potassium salt of indole-3-butyric acid (K-IBA) or 1-naphthaleneacetic acid (NAA) at varying concentrations to determine if a commercially viable protocol could be developed. Comparing cuttings taken from container-grown mature stock plants and juvenile seedlings, propagules originating from mature plants resulted in higher survival, likely because of enhanced carbohydrate reserves and photosynthetic capacity. Exogenous auxin (K-IBA or NAA) treatments had no effect on cutting survival or root number and length. The only growth parameter influenced by a specific hormone and concentration was cutting height, which was greater when K-IBA at 1000 or 3000 ppm concentrations were employed, compared to the control with no hormone applied. Ultimately, vegetative propagation can be achieved with commercially acceptable success using no exogenous hormone application.

Lewis M, Chappell M, Thomas PA, Zhang D, Greyvenstein O. 2020. Development of a vegetative propagation protocol for Asclepias tuberosa. Native Plants Journal 21(2):27-34.

\section{KEY WORDS}

cutting propagation, native plant, butterfly weed, Apocynaceae, Asclepiadaceae, indole-3butyric acid, 1-naphthaleneacetic acid

\section{NOMENCLATURE}

Plants: University of Georgia Center for Invasive Species and Ecosystem Health (2019)

Plants: USDA NRCS (2019)

Insects: ITIS (2019)

Photos by Mary Lewis 
ommercial production of ornamental herbaceous perennial crops relies on 3 methods of plant propagation: seed, vegetative (stem) cuttings, or tissue culture. Of these methods, vegetative propagation ensures the preservation of a particular genotype (cultivar) over many production cycles. Vegetative propagation also affords growers a shorter production cycle and more uniform crop growth compared to seed production (Ecker and Barzilay 1993). A majority of clonal propagules are derived from cuttings because minimal infrastructure is required, compared to tissue culture, to achieve a high rate of success once a protocol is available for the species and (or) cultivar.

Milkweed (Asclepias L.), a member of the Apocynaceae family (Asclepiadaceae being a subfamily), contains 108 species that are found exclusively in North America (Woodson 1954). The genus is recognized as an important pollinator taxa to many butterfly species, as well as a forage source for butterfly larvae, particularly the monarch butterfly (Danaus plexippus [Lepidoptera: Nymphalidae]) (Hutchings 1923; Brower 1969). Many Asclepias spp. also possess landscape value, having extended flowering periods and considerable drought tolerance relative to other summer-flowering herbaceous perennials.

Asclepias spp. undergo reproduction in the wild by 2 avenues: seed and rhizomatous tubers (Luna and Dumroese 2013). Propagation from seed does not allow for maintenance of cultivars, as seedling embryos undergo genetic recombination. Furthermore, many Asclepias spp., such as common milkweed (Asclepias syriaca L.), require an extended seed dormancy period of a year or more combined with cold stratification before a germination rate of $50 \%$ or greater can be achieved (Groh 1943; Baskin and Baskin 1977). Such requirements, in addition to seedling phenotypic variability and uneven germination timing, have likely contributed to limited commercial production of Asclepias spp.

Much of what is known about Asclepias biology and propagation is based on studies of Asclepias syriaca (Bhowmik and Bandeen 1976) in natural environments. Other studies have vague or incomplete methodology. Propagation protocols have been developed to facilitate production of other Asclepias spp., including the federally threatened Mead's milkweed (Asclepias meadii Torr.) (Bhowmik and Bandeen 1970, 1976; Bowles and others 1991) and Asclepias syriaca (Bandeen and Bhowmik 1973; Luna and Dumroese 2013); yet these protocols focus on tuber and seed propagation. Of the few detailed studies that have been published on vegetative propagation protocols for Asclepias, development of optimum environmental conditions to initiate callus and root development during propagation were the focal areas (Ecker and Barzilay 1993). Across species, Asclepias propagules were found to root and achieve optimal growth in well-drained soils (to mitigate pathogen pressure) and when exposed to 15 to $17 \mathrm{~h}$ of day length with temper- atures ranging from 16 to $25^{\circ} \mathrm{C}\left(61-77^{\circ} \mathrm{F}\right)$ night/day (Ecker and Barzilay 1993; Luna and Dumroese 2013).

Vegetative propagation has historically been fostered by employing various (synthetic) auxin hormones to expedite the formation of callus and root initials that improve rooting uniformity. A study by Bowles and others (1991) treated stem cuttings of 2 Asclepias spp. with $1000 \mathrm{ppm}$ and $4000 \mathrm{ppm}$ concentrations of indole-3-butyric acid (IBA). Both treatments resulted in approximately $40 \%$ rooting success (Bowles and others 1991), an unacceptable rate for commercial production. The time at which cuttings are taken can affect cutting survivability. Phillips (1985) indicated the best time to collect Asclepias spp. stem cuttings was 3 to $5 \mathrm{wk}$ prior to flower initiation, or 3 to $4 \mathrm{wk}$ after dormancy break.

Asclepias tuberosa L. was employed as the model species in this study as it is the most widely produced species in commercial floriculture. An optimized vegetative propagation protocol would allow commercial growers to increase the production of A. tuberosa. A study conducted by Bowles and others (1991) failed to develop a propagation protocol for A. tuberosa when utilizing IBA concentrations at or below $4000 \mathrm{ppm}$. This study hypothesized that stronger concentrations of rooting compounds would lead to increased plant regeneration and greater rooting success.

\section{MATERIALS AND METHODS}

\section{Container Stock Plant Production}

Seed was initially collected in 2015 from a single maternal parent randomly selected in a naturally occurring population in Oglethorpe County, Georgia $\left(33.875460{ }^{\circ} \mathrm{N},-83.211567\right.$ ${ }^{\circ} \mathrm{W}$ ) and germinated in July 2016. From these seedlings, 100 A. tuberosa stock plants were generated as rooted cuttings in July 2017 and were transplanted into 3.8-1 (1-gal) containers (Classic 400, Nursery Supply, Agawam, Massachusetts) in September 2017. Plants were maintained and overwintered outdoors at the University of Georgia Athens campus (33.9480 ${ }^{\circ} \mathrm{N}, 83.3773^{\circ} \mathrm{W}$; USDA Zone 8a) on an outdoor gravel pad. On 3 March 2018, plants were transferred to a climate-controlled chamber held at $2{ }^{\circ} \mathrm{C}\left(35.6^{\circ} \mathrm{F}\right)$. After 8 wk in cold storage, plants were moved into a controlled environment greenhouse with the temperature set to 24 to $29^{\circ} \mathrm{C}\left(75.2-84.2^{\circ} \mathrm{F}\right)$ night/day with 14-h day length. These 3.8-1 (1-gal) plants were used as the source of cuttings harvested from mature stock plants. Six weeks after stock plants had broken dormancy (18 June 2018), yet prior to floral initiation, vegetative cuttings were harvested.

\section{Seedling Stock Plant Production}

Seeds were collected from a controlled one-way cross (of 2 genotypes) of A. tuberosa. The parent plants originated from the same wild-collected population in Oglethorpe County, Georgia, and were used to generate stock plants from which 
mature cuttings were harvested. This method minimized confounding results that could be the result of genotype $\times$ environment interaction, although we do recognize it is impossible to completely mitigate these interactions when working with a seedling population that has undergone genetic recombination. Immediately after harvesting, seed was cold stratified for $30 \mathrm{~d}$ at $2{ }^{\circ} \mathrm{C}\left(35.6^{\circ} \mathrm{F}\right)$ and planted into seedling trays (STI-804, T O Plastics, Minneapolis, Minnesota) on 1 May 2018. Seeds germinating between 23 May and 30 May 2018 were selected as stock material for cuttings from juvenile plants at $14 \mathrm{wk}$ after germination.

\section{Experimental Design}

Cuttings were harvested from plants at 2 different maturities, which represent a treatment effect. The first cuttings were propagules collected from mature containerized stock plants at $6 \mathrm{wk}$ after exiting dormancy (mature cutting), and the second cuttings were harvested from juvenile plants $14 \mathrm{wk}$ after germination (juvenile cutting). All cuttings were taken from leafy apical shoot tips, approximately $5 \mathrm{~cm}$ (2.0 in) in length. Cuttings contained 3 nodes and were propagated with $2.0 \mathrm{~cm}(0.8 \mathrm{in})$ of stem (containing 1 node) below the soil line and $3 \mathrm{~cm}$ (1.2 in) of stem (and 2 nodes) above the soil line (Figure 1). This study utilized 90\% sand (Lowe's All-Purpose Builder's Sand, Charlotte, North Carolina) and $10 \%$ peat (Sungro Peat Moss Grower Grade Orange, Agwam, Massachusetts) as a rooting medium to enhance porosity and reduce soilborne diseases (Ecker and Barzilay 1993; Luna and Dumroese 2013). Cuttings were taken between 7:00 and 8:00 am and immediately placed into cold

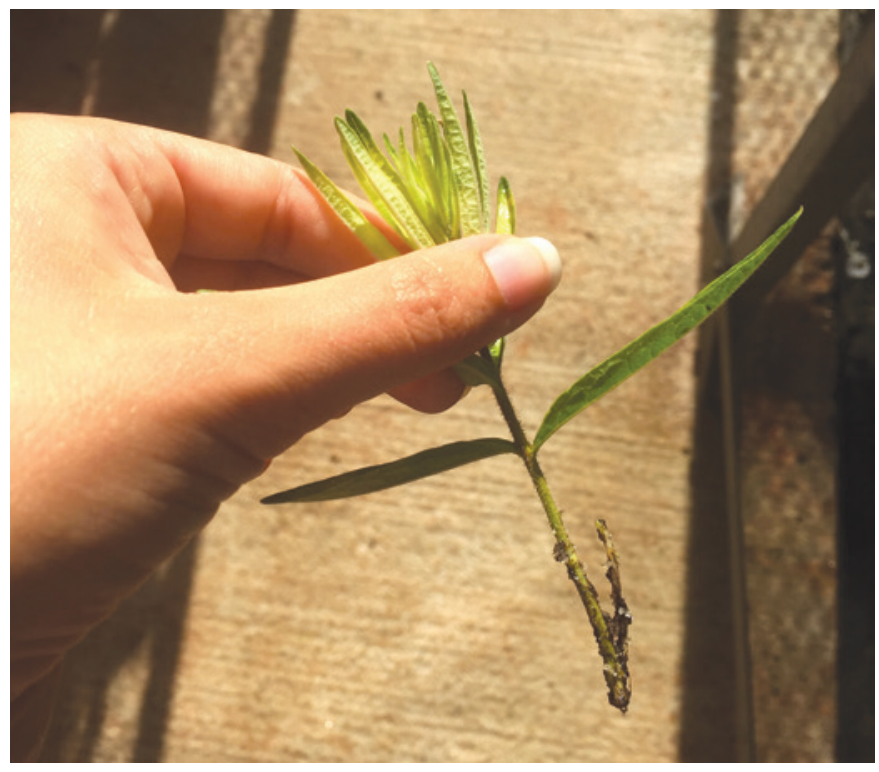

Figure 1. Photo of a propagule at the midpoint of the study ( $4 \mathrm{wk}$ after striking). Cuttings were initially 3 nodes in length and frequently resumed growth via axillary bud break or re-initiating growth from apical meristem while in the propagation environment. water mixed with $10 \%$ hydrogen peroxide to maintain turgor and provide surface sterilization.

Two rooting compounds, K-IBA (Hortus USA, New York) and laboratory-grade NAA (Sigma-Aldrich, St Louis, Missouri), at differing concentrations represented the second treatment effect. We applied K-IBA as a liquid dip at 0 ppm, a 50 ppm basal soak of $24 \mathrm{~h}$, and quick (5-s) dips at $1000 \mathrm{ppm}, 3000 \mathrm{ppm}$, $5000 \mathrm{ppm}$, and $8000 \mathrm{ppm}$. We applied NAA as a liquid (5-s) dip at $500 \mathrm{ppm}, 1000 \mathrm{ppm}, 1500 \mathrm{ppm}$, and $2000 \mathrm{ppm}$. Both hormones were dissolved in deionized water. We replicated each treatment combination 4 times, with 25 cuttings per replication. Immediately after all cuttings were excised from stock plants, cuttings were re-cut to the appropriate length, treated with hormone, and struck in 804 inserts each having 32-cells (BWI, Greer, South Carolina) held inside 1020 greenhouse trays (BWI) (Figure 2). Once cuttings were struck in 32-cell trays, replications were placed in a randomized complete block design on a mist bench covered with $60 \%$ shade cloth. Misting source for all treatments was municipal water $(\mathrm{pH}$ 6.8, alkalinity $9 \mathrm{mg} / \mathrm{l}$ ) applied via NetaFim Vibromist nozzles (NetaFim USA, Fresno, California) every $6 \mathrm{~min}$ for $10 \mathrm{~s}$. The misting system also delivered 20-10-20 NPK (Harrell's, Lakeland, Florida) + STEM (Peters, Dublin, Ohio) fertigation mixture to the cuttings at 50 ppm $\mathrm{N}$ every $5 \mathrm{~d}$ for a 2 -h window for the duration of the study. Misting was applied only from sunrise to sunset. While under mist, greenhouse conditions were kept between 24 and $29^{\circ} \mathrm{C}\left(75.2\right.$ and $\left.84.2^{\circ} \mathrm{F}\right)$ day/night with 13 to $14 \mathrm{~h}$ of natural day length. To prevent root pathogens, a soil drench fungicide rotation of Subdue MAXX (mefenoxam, Syngenta Crop Production, Greensboro, North Carolina; FRAC Code 4) and Heritage (azoxystrobin, Syngenta Crop Production; FRAC Code 11) was used in rotation and applied every $14 \mathrm{~d}$.

\section{Data Collection and Statistical Analysis}

Destructive harvest occurred $8 \mathrm{wk}$ after cuttings were struck (Figure 3) and data immediately collected. Measurements included rooting (success/fail), plant height from the soil line $(\mathrm{cm})$, number of roots, and length of the longest root $(\mathrm{cm})$. Statistical analysis was performed using JMP (v. 13.0, SAS Institute, Cary, North Carolina). We analyzed data from juvenile and mature cuttings separately to determine treatment significance between hormones and among concentrations. One-way Analysis of Variance (ANOVA) and separation of treatment means with Tukey's HSD were used to analyze plant height, root number, and root length. Rooting success data from juvenile and mature cuttings were analyzed together using oneway Analysis of Variance (ANOVA) to determine maturity and concentration as treatment effects. Separation of treatment means with Tukey's HSD and pairwise comparisons by hormone type were used to determine significance level. We reported only data that shows significant difference among treatment combinations. 


\section{RESULTS AND DISCUSSION}

Methodology for this study was based on commercially accepted protocols, including the use of intermittent misting and exogenous (K-IBA and NAA) hormone application. Informally surveying 10 floriculture growers indicated that the maximum time window allotted in the propagation of a herbaceous crop was 6 to $8 \mathrm{wk}$, and all growers perform propagation under 50 to $70 \%$ shade with intermittent mist (data not shown). The use of intermittent misting in A. tuberosa was also consistent with results from Phillips (1985) and Grabowski (1996) that stressed the necessity of high humidity levels throughout the propagation cycle of Asclepias spp. to maximize rooting success.

Results of studies by Phillips (1985) and Grabowski (1996) indicated cuttings had increased success when taken before floral initiation. Preliminary experimentation as part of this study indicated that $6 \mathrm{wk}$ after breaking dormancy was the optimal time to harvest cuttings from mature stock plants prior to floral initiation (data not shown). Successful propagation using juvenile seedlings of $A$. tuberosa has yet to be reported, yet in many perennial taxa, cuttings from juvenile tissue afforded higher success (Borchert 1975). Data from the two trials utilizing cuttings from stock plants of differing maturities were combined to assess if age of the propagule had any influence on rooting success. Stock plant age affected rooting success, re-

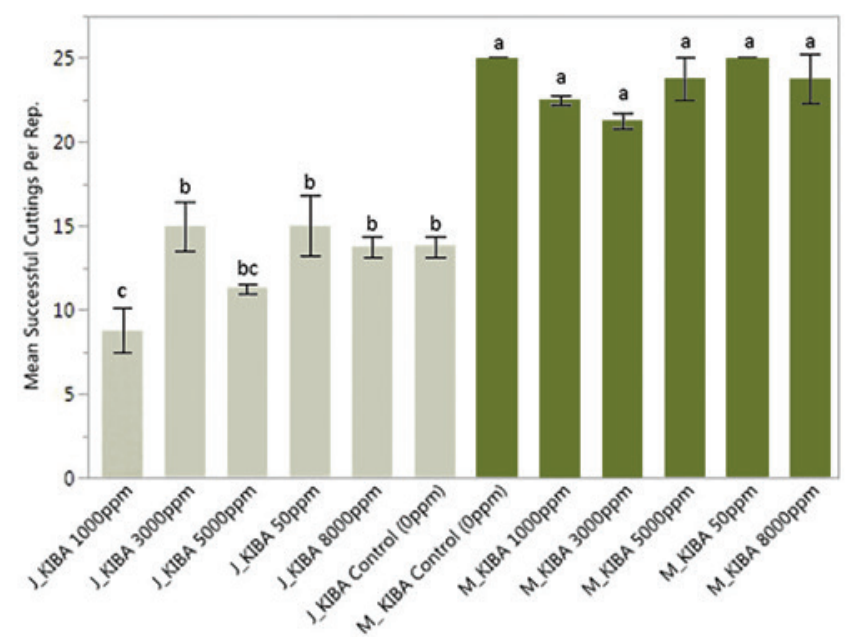

Maturity/K-IBA Hormone Concentration (ppm)

Figure 4. Effect of cutting maturity on rooting success with K-IBA. With 25 successful cuttings possible per repetition, comparisons among hormone concentrations and maturity are displayed. Lighter bars (left) indicate all juvenile cuttings at differing K-IBA (potassium salt of indole-3-butyric acid) concentrations. Dark bars (right) indicate mature cuttings at differing K-IBA concentrations. Cutting age is defined as propagules harvested from 2-y-old stock plants $6 \mathrm{wk}$ after breaking dormancy (M: mature) and cuttings harvested from seedlings $14 \mathrm{wk}$ after germination (J: juvenile). Bars represent means with standard error based on standard one-way ANOVA. Treatment groups (columns) not sharing a letter are significantly different at $P=0.05$ level based on adjusted $P$ values using Tukey's HSD. gardless of the hormone applied (Figures 4 and 5; $P<0.0001$ ). Propagules harvested from mature stock plants treated with K-IBA had greater overall success $(85-100 \%)$ than did those collected from juvenile seedlings $(25-60 \%)$ and treated with K-IBA (Figure 4; $P<0.001$ ). Our results contradict those of Bowles and others (1991) who found no difference in success rate when comparing stem cuttings from mature A. syriaca and juvenile green comet milkweed (A. viridiflora Raf.) treated with 2 IBA concentrations. Bowles and others (1991) utilized IBA dissolved in alcohol solution (1000 ppm and $4000 \mathrm{ppm}$ ). Alcoholbased solutions can damage plant tissue and therefore reduce success. The current study employed commercial production protocols using a larger range of hormone concentrations as well as K-IBA dissolved in deionized water rather than alcohol. This single factor could explain contradictory results between Bowles and others' (1991) results and those of this study.

Trends observed among different NAA concentrations paralleled those observed in K-IBA treatments. Success was enhanced in cuttings obtained from mature stock (80-100\%) when compared to juvenile cuttings. The exception was juvenile cuttings treated with $1500 \mathrm{ppm}$ NAA (85\%) (Figure 5; $P<0.001)$. Differences within cutting age groups to differing auxin treatment were not surprising. NAA has a similar mode of uptake, translocation, and metabolic activity as K-IBA, despite having a lower binding affinity with auxin receptors than

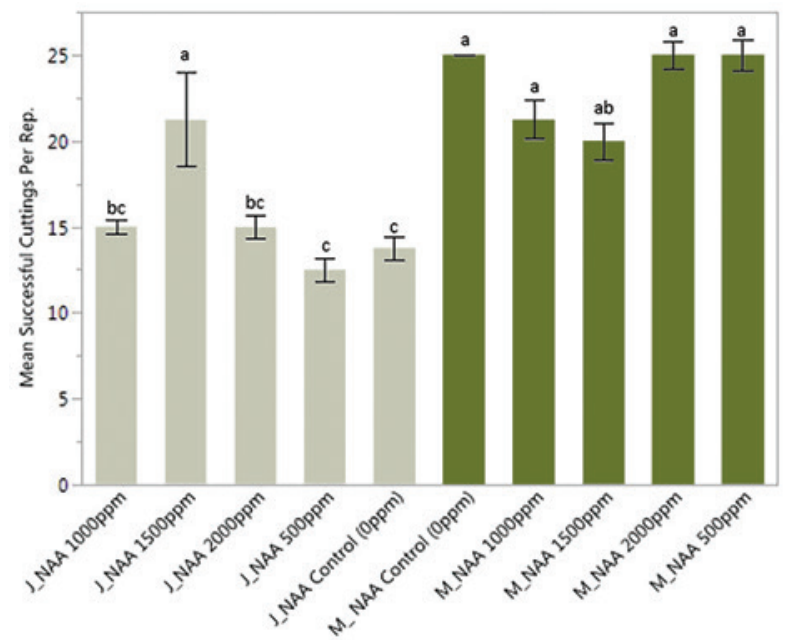

Maturity/NAA Hormone Concentration (ppm)

Figure 5. Effect of cutting maturity on rooting success with NAA. With 25 successful cuttings possible per repetition, comparisons among hormone concentrations and maturity are displayed. Lighter bars (left) indicate all juvenile cuttings at differing NAA (laboratory grade, 1-naphthaleneacetic acid) concentrations. Dark bars (right) indicate mature cuttings at differing NAA concentrations. Cutting age is defined as propagules harvested from 2-y-old stock plants 6 wk after breaking dormancy (M: mature) and cuttings harvested from seedlings $14 \mathrm{wk}$ after germination (J: juvenile). Bars represent means with standard error based on standard one-way ANOVA. Treatment groups (columns) not sharing a letter are significantly different at $P=0.05$ level based on adjusted $P$ values using Tukey's HSD. 
K-IBA and a longer (yet slower response) efficacy period (Blythe and others 2004; Pacurar and others 2014). For this reason, many commercial operations use a combination of K-IBA and NAA to maximize the period of uptake potential. Propagules obtained from mature plants also had greater stem diameter and larger leaves compared to seedling-derived propagules (data not shown). As a result, we assume these propagules had greater carbohydrate reserves and photosynthetic capacity compared to cuttings obtained from seedlings. Both stored and cutting-produced carbohydrates have been shown to directly influence rooting success of leafy stem cuttings in other taxa (Leakey 2004) and was likely the cause for reduced success in propagules obtained from juvenile seedlings in the present study.

Despite observing differences in rooting success rates of mature versus juvenile cuttings, hormone concentration surprisingly had little effect on rooting success. Compared to the control treatment, there was no difference in rooting success of propagules treated with varying hormone concentrations that originated from mature stock plants $(P<0.001)$ (Figures 4 and 5). This trend was also true for juvenile cuttings $(P<0.001)$, with the exception of the NAA at $1500 \mathrm{ppm}$ treatment, which had a success rate of $85 \%$ compared to the control at $55 \%(P<0.001)$ (Figure 5). Studies on a number of taxa have shown that exogenous auxins increase the speed of adventitious root formation (Leakey 2004) as well as rooting uniformity (De Klerk and others 1999; Ramtin and others 2011); yet that did not seem to be the case for A. tuberosa. Although the use of rooting hormones is common, many herbaceous taxa have been documented as not requiring rooting compounds to achieve commercially acceptable levels of success (Ford and others 2002; Hawkins and others 2013).

Greater root number, root length, and final plant height are typically linked to vegetative propagule quality (Hawkins and others 2013). When assessing juvenile cuttings, no differences were observed in the mean number of roots $(P=0.8)$, root length $(P=0.1)$, or plant height $(P=0.1)$ regardless of hormone or concentration on juvenile cuttings (data not shown). Additionally, mean values of number of roots, root length, and plant height were universally lower than the mature cuttings (data not shown). When assessing mature cuttings, no differences were observed in mean root number $(P=0.02)$ or root length $(P=0.05)$ regardless of hormone type (Table 1$) . \mathrm{K}-\mathrm{IBA}$ at 3000 ppm produced the greatest number of roots $(11.94 \mathrm{~cm} \pm 1.35$ [4.70 in \pm 0.53$]$ ), but that value did not differ from the control $(9.19 \mathrm{~cm} \pm 1.32$ [3.61 in \pm 0.52$]$ ) (Table 1). These results concur with Davies and others (2011), which generalized A. tuberosa is an easy-to-root species. Differences were observed in mean plant height, with $1000 \mathrm{ppm} \mathrm{K-IBA}(6.20 \mathrm{~cm} \pm 0.41$ [2.44 in \pm $0.16 \mathrm{in}])$ and $3000 \mathrm{ppm} \mathrm{K-IBA}(7.94 \mathrm{~cm} \pm 0.42$ [3.12 in \pm 0.16$])$ having the greatest observed plant height $6 \mathrm{wk}$ after striking (Table 1; $P<0.001)$. Similarly, Parađiković and others (2013) reported that the application of K-IBA increased plant height in kitchen sage (Salvia officinalis L. [Lamiaceae]) and rosemary (Rosmarinus officinalis L. [Lamiaceae]) despite not enhancing root elongation. Considering that K-IBA at $1000 \mathrm{ppm}$ and 3000

TABLE 1

Effect of hormone type (K-IBA or NAA) and concentration on the mean number of roots, root length, and plant height at harvest (8 wk after striking).

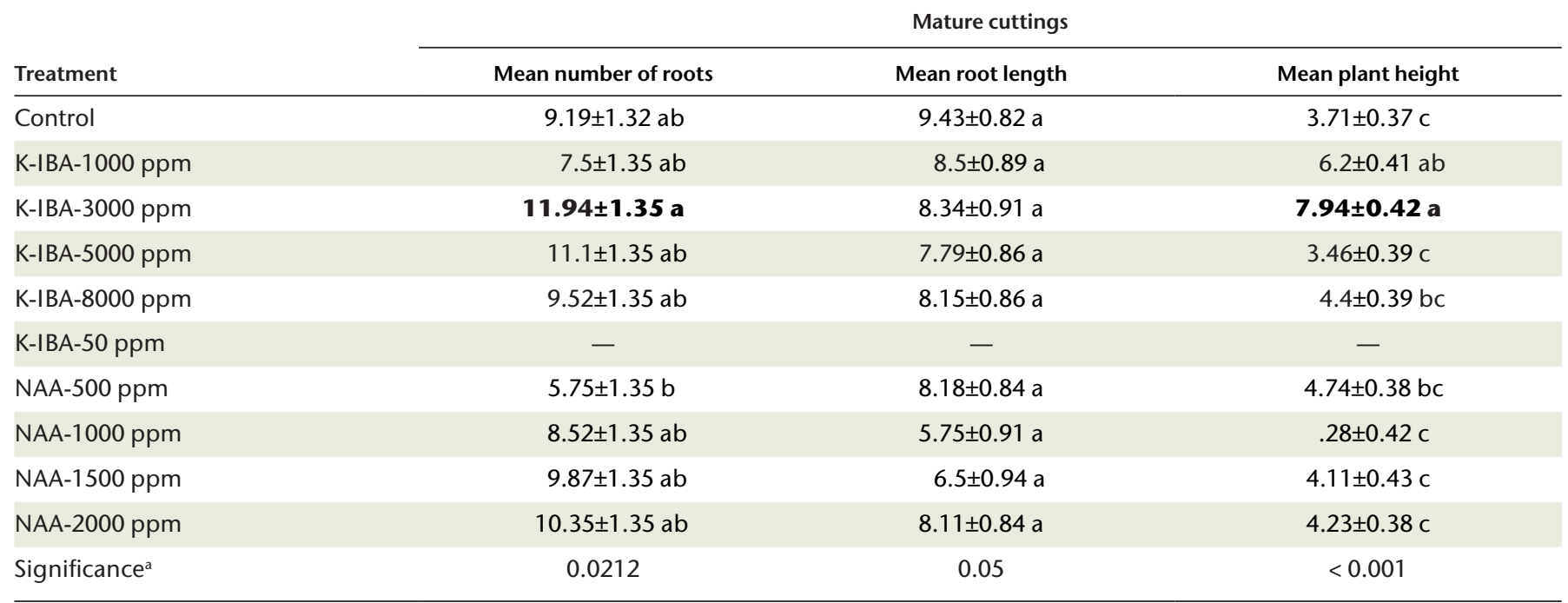

Notes: Results depicted apply only to propagules collected from mature (2-y-old) stock plants collected and struck 6 wk after breaking dormancy yet prior to floral initiation. All values are reported in $\mathrm{cm}: 1 \mathrm{~cm}=0.4 \mathrm{in}$. Standard error of the means are reported in addition to means. K-IBA $=$ indole-3-butyric acid; NAA = 1-naphthaleneacetic acid.

a Significance of treatment effects $(P>\mathrm{F}$; ns = not significant at the 0.05 level). Means in same treatment group (columns) not sharing a letter are significantly 
ppm only positively influenced plant height in this study (not root number or length), these concentrations would be recommended only to propagators wishing to produce taller liners (Table 1). When assessing all 3 growth parameters, note that NAA did not outperform the control and would thus not be recommended for the propagation of $A$. tuberosa from mature stock plants (Table 1). Equivalent cutting responses in NAAtreated and non-treated cuttings have been reported in a variety of herbaceous and woody taxa by Salaš and others (2013), Tchinda and others (2013), Yan and others (2017), and Nagalakshmi and others (2018).

\section{CONCLUSION}

This article is a novel documentation of a detailed (and commercially viable) cutting propagation protocol for $A$. tuberosa. To date, several research reports have addressed cutting propagation protocols for an Asclepias spp., yet no study has provided a detailed methodology for successful regeneration at a commercially viable level. The goal of our study was to examine 2 water-based rooting hormones (K-IBA and NAA) applied to both mature (2-y-old) and juvenile (seedling) stem cuttings of $A$. tuberosa. Results indicated that cuttings taken from mature plants resulted in commercially acceptable rooting success. This outcome was likely because of greater carbohydrate reserves and photosynthetic ability of cuttings obtained from mature stock plants. We also observed that regardless of hormone used (K-IBA or NAA) or concentrations applied, no overall improvement occurred in cutting survival or root growth parameters (root number or length) compared to the control that had no hormone applied. The only growth parameter positively influenced by an exogenous auxin application was cutting height, which was greatest at 1000 or $3000 \mathrm{ppm}$ K-IBA. Translating our findings into practical application, results indicate that no rooting hormone is needed when sourcing cuttings from mature stock plants that are taken between emergence from dormancy and floral initiation. These findings should afford commercial and conservation-based producers of $A$. tuberosa a more rigid, science-based, simplified, and cost-effective propagation protocol. As Asclepias contains 108 recognized species, this study should also afford propagators and researchers of Asclepias spp. a platform on which to base future studies. With a successful vegetative propagation protocol established, future propagation studies of A. tuberosa that focus on development of tissue culture protocols could further enhance commercial production of elite genotypes and enhance conservation efforts.

\section{ACKNOWLEDGMENTS}

We appreciate the support of Ball Horticultural Company, Foothills Compost, Pan American Seed, Harrell's Fertilizers, and the University of Georgia Research Foundation for support of this project. We also appreciate internal manuscript reviews provided by John Ruter and Cain Hickey.

\section{REFERENCES}

Bandeen JD, Bhowmik PC. 1973. Common milkweed control. Canadian National Weed Commission East. Section Proceedings 292.

Baskin JM, Baskin CC. 1977. Germination of common milkweed (Asclepias syriaca L.) seeds. Bulletin of the Torrey Botanical Club 104:167170.

Bhowmik PC, Bandeen JD. 1970. Life history of common milkweed (Abstract). Champaign (IL): Weed Science Society of America. p 6.

Bhowmik PC, Bandeen JD. 1976. The biology of Canadian weeds. 19. Asclepias syriaca L. Canadian Journal of Plant Sciences 56:579-589.

Blythe EK, Sibley JL, Ruter JM, Tilt KM. 2004. Cutting propagation of foliage crops using a foliar application of auxin. Scientia Horticulturae 103:31-37.

Borchert R. 1975. Differences in shoot growth patterns between juvenile and adult trees and their interpretation based on systems analysis of trees. In: Zimmerman RH, editor. Symposium on Juvenility in Woody Perennials 56:123-130. Leuven, Belgium: International Society for Horticultural Science.

Bowles M, Betz R, Flakne R. 1991. Report on vegetative propagation of Mead's milkweed (Asclepias meadii) and propagation from cuttings of common milkweed (Asclepias syriaca) as a surrogate for Mead's milkweed. Lisle (IL): Morton Arboretum.

Brower LP. 1969. Ecological chemistry. Scientific American 220:22-28.

Davies FT, Geneve RL, Kester DE, Hartmann HT. 2011. Hartmann and Kester's plant propagation: principles and practice. 8th edition. Boston (MA): Prentice Hall.

De Klerk GJ, Van der Krieken W, deJong JC. 1999. Review the formation of adventitious roots: new concepts, new possibilities. In Vitro Cellular \& Developmental Biology-Plant 35:189-199.

Ecker R, Barzilay A. 1993. Propagation of Asclepias tuberosa from short root segments. Scientia Horticulturae 56:171-174.

Ford YY, Bonham EC, Cameron RWF, Blake PS, Judd HL, HarrisonMurray RS. 2002. Adventitious rooting: examining the role of auxin in an easy- and a difficult-to-root plant. Plant Growth Regulation 36:149-159.

Grabowski JM. 1996. Growing butterfly milkweed. Publications of the Jamie L Whitten Plant Materials Center. Tillatoba (MS): USDA Natural Resources Conservation Service.

Groh H. 1943. Notes on common milkweed. Science Agriculture 23:625-632.

Hawkins SM, Chappell M, Martin MT Jr. 2013. Defining a protocol for vegetative propagation of Baptisia, Eupatorium and Thermopsis. Journal of Environmental Horticulture 31:162-168.

Hutchings CB. 1923. A note of the monarch or milkweed butterfly with special reference to its migratory habits. Canadian Field Naturalist 37:150.

[ITIS] Integrated Taxonomic Information System. 2019. Online database. URL: http://www.itis.gov (accessed Dec 2019). Washington (DC): National Museum of Natural History.

Leakey RR. 2004. Physiology of vegetative reproduction. Encyclopedia of Forest Sciences. London: Academic Press. p 1655-1688.

Luna T, Dumroese RK. 2013. Monarchs (Danaus plexippus) and milkweeds (Asclepias species): the current situation and methods for propagating milkweeds. Native Plants Journal 14:5-15. 
Nagalakshmi MAH, Sahana V, Prasanna KT. 2018. Vegetative propagation and initial growth performance of Streblus asper Lour.-a tropical medicinal tree. Journal of Experimental Biological and Agricultural Sciences 6:606-612.

Pacurar DI, Perrone I, Bellini C. 2014. Auxin is a central player in the hormone cross-talks that control adventitious rooting. Physiologia Plantarum 151:83-96.

Parađiković N, Zeljković S, Tkalec M, Vinković T, Dervić I, Marić M. 2013. Influence of rooting powder on propagation of sage (Salvia officinalis L.) and rosemary (Rosmarinus officinalis I.) with green cuttings. Poljoprivreda 19:10-15.

Phillips HR. 1985. Growing and propagating wild flowers. Chapel Hill (NC): University of North Carolina Press.

Ramtin A, Khalighi A, Hadavi E, Hekmati J. 2011. Effect of different IBA concentrations and types of cuttings on rooting and flowering Poinsettia pulcherrima L. International Journal of Agricultural Science 1:303-310.

Salaš P, Sasková H, Mokričková J, Litschmann T. 2013. Evaluation of different types of rooting stimulators. Acta Universitatis Agriculturae et Silviculturae Mendelianae Brunensis 60:217-228.

Tchinda ND, Messi HJCM, Nzweundji G, Tsabang N, Dongmo B, Oumar D, Tarkang PA, Caver A, Ndoumou DO. 2013. Improving propagation methods of Ricinodendron heudelotti Baill. from cuttings. South African Journal of Botany 88:3-9.

University of Georgia Center for Invasive Species and Ecosystem Health. Bugwood image database system. URL: http://images .bugwood.org (accessed 10 Oct 2019). Tifton (GA).

[USDA NRCS] USDA Natural Resources Conservation Service. The PLANTS database. URL: http://plants.usda.gov (accessed 10 Oct 2019). Greensboro (NC): National Plant Data Team.

Woodson RE. 1954. The North American species of Asclepias L. Ann. Missouri Botanical Garden 41:1-211.

Yan SP, Yang RH, Wang F, Sun LN, Song XS. 2017. Effect of auxins and associated metabolic changes on cuttings of hybrid aspen. Forests 8:117.

\section{AUTHOR INFORMATION}

\section{Mary Lewis}

Graduate Student

snowbery@uga.edu

Matthew Chappell

Associate Professor

hortprod@uga.edu

\section{Paul A Thomas}

Professor

pathomas@uga.edu

\section{Donglin Zhang}

Professor

donglin@uga.edu

University of Georgia

Department of Horticulture

1111 Miller Plant Science Building

Athens, GA 30602

\section{Ockert Greyvenstein}

Plant Breeder

OGreyvenstein@ballhort.com

Ball Horticultural Company

400 Obispo Street

Guadalupe, CA 93434

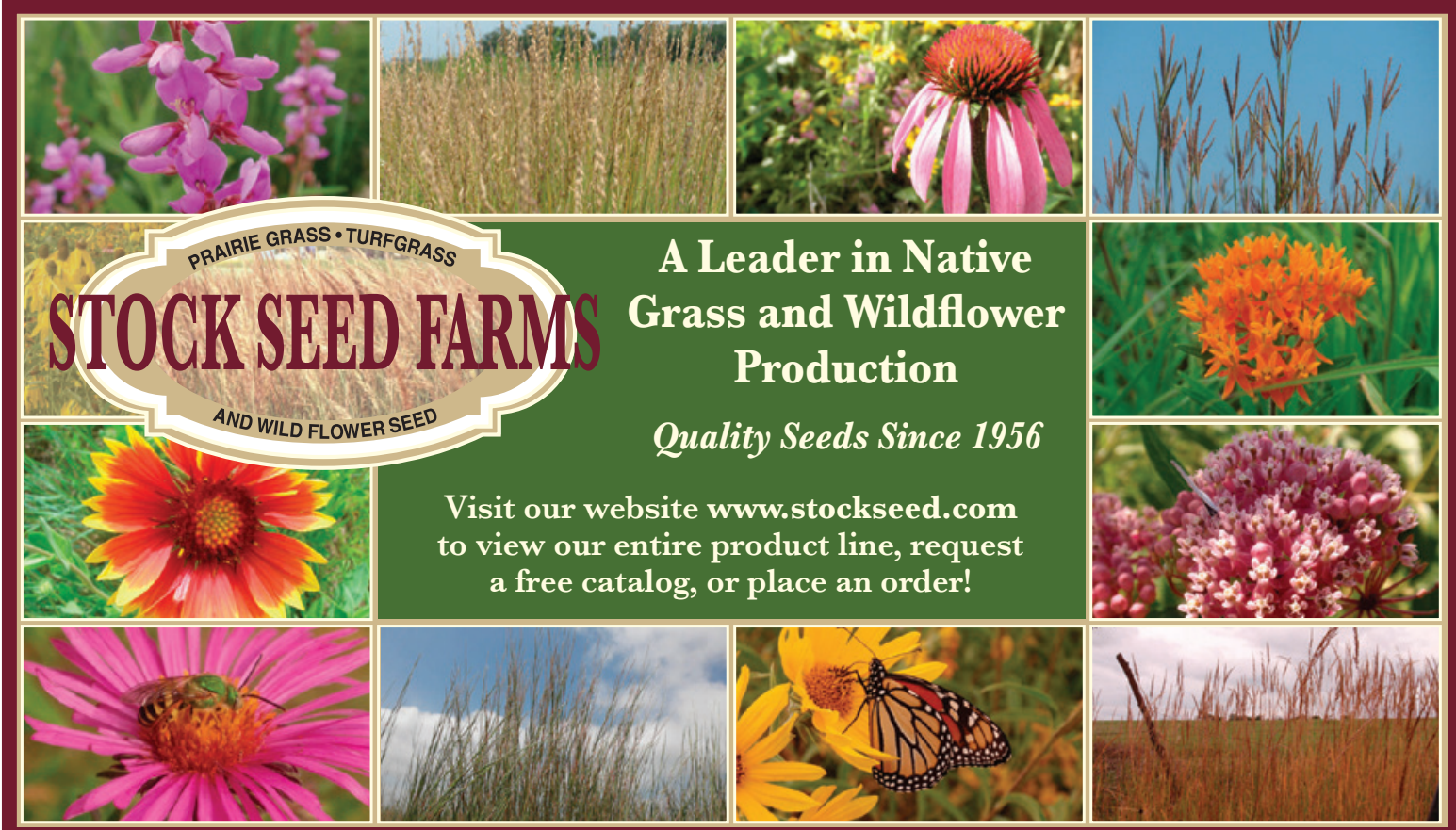

Email: prairie@stockseed.com • Phone: 800-759-1520 28008 Mill Road Murdock, NE 68407 